\title{
Resposta imunológica em caprinos vacinados contra agalaxia contagiosa $^{1}$
}

\author{
Maria Dalva B. Alcântara², Ana Claudia Campos³ ${ }^{3}$ Marcia A. Melo, José M. Pereira Filho4, \\ Elmiro R. Nascimento ${ }^{5}$, Aderaldo A. Farias ${ }^{2}$, Dalana R.M. Sousa ${ }^{4}$ e Edisio O. Azevedo ${ }^{4 *}$
}

\begin{abstract}
Alcântara M.D.B., Campos A.C., Melo M.A., Pereira Filho J.M., Nascimento E.R., Farias A.A., Sousa D.R.M. \& Azevedo E.O. 2013. [Immune response in goats vaccinated against contagious agalactia.] Resposta imunológica em caprinos vacinados contra agalaxia contagiosa. Pesquisa Veterinária Brasileira 33(5):561-564. Laboratório de Vacinas e Diagnóstico, Unidade Acadêmica de Medicina Veterinária, Universidade Federal de Campina Grande, Av. Universitária s/n, Santa Cecília, Patos, PB 58708-110, Brazil. E-mail: edisio@pq.cnpq.br

This study aimed to evaluate the efficacy of two inactivated vaccines against contagious agalactia containing adjuvant oily and watery. For this, 73 goats were divided in two experiments. In the experiment I was verified the vaccine safety and 15 goats were divided into three experimental groups of five animals each. A1 and B1 groups were immunized with vaccine containing either aluminum or oil, respectively, and group $\mathrm{C}$ was the control group without immunization. In the experiment II, the immune response against the vaccines was evaluated by immunization of 58 goats that were divided in to two groups: group A2, 28 animals were immunized with the aluminum based vaccine; and group B2, 30 animals were immunized with the oil based vaccine. In the experiment II, the animals received a third dose on 180 day after the second dose. Antibody levels were determined by indirect ELISA from ssamples collected on vaccination days and on 30 day after the second dose (Experiment I) and on 30 day after the third dose (Experiment II). The animals from B1 and B2 groups (oil based vaccine) demonstrated higher antibody levels $(\mathrm{P}<0.05)$ than $\mathrm{A} 1$ and A2 (aluminum based vaccine) in both experiments.
\end{abstract}

INDEX TERMS: Mycoplasma agalactiae, contagious agalactia, immunology, adjuvant, antibodies, vaccines, goats.

RESUMO.- Este trabalho teve como objetivo avaliar a eficiência de duas vacinas inativadas contra agalaxia contagiosa contendo adjuvante oleoso e aquoso. Para tanto, foram utilizados 73 caprinos, agrupados em dois experimentos. No experimento I, para avaliar a inocuidade das vacinas, foram utilizados 15 caprinos, subdivididos em três grupos

\footnotetext{
${ }^{1}$ Recebido em 6 de outubro de 2012.

Aceito para publicação em 18 de dezembro de 2012.

${ }^{2}$ Empresa Estadual de Pesquisa Agropecuária da Paraiba (Emepa), Rua Eurípedes Tavares 210, Tambiá, João Pessoa, PB 58013-290, Brasil.

${ }^{3}$ Laboratório de Viroses, Departamento de Medicina Veterinária, Universidade Federal Rural de Pernambuco (UFRPE), Rua Dom Manoel de Medeiros s/n, Dois Irmãos, Recife, PE 52171-900, Brasil.

${ }^{4}$ Unidade Acadêmica de Medicina Veterinária, Universidade Federal de Campina Grande (UFCG), Av. Universitária s/n, Santa Cecília, Patos, PB 58708-110, Brasil. *Autor para correspondência: edisio@pq.cnpq.br

${ }^{5}$ Departamento de Saúde Coletiva Veterinária e Saúde Pública, Universidade Federal Fluminense (UFF), Rua Vital Brasil Filho 64, Vital Brasil, Niteroi, RJ 24230-340, Brasil.
}

de cinco animais cada, sendo que o grupo A1 foi imunizado com a vacina aquosa, o grupo B1 com a vacina oleosa e o grupo C não imunizado, foi o controle. No experimento II, para avaliar a resposta imune foram utilizados 58 caprinos, subdivididos em dois grupos, sendo o grupo A2, com 28 animais imunizados com a vacina aquosa e o grupo B2, com 30 animais imunizados com a vacina oleosa. Os animais do experimento II receberam uma terceira dose, 180 dias após a segunda dose vacinal. Os níveis de anticorpos foram determinados por ELISA indireto, realizado no dia de cada vacinação e 30 dias após a segunda dose (experimento I) e 30 dias após a terceira dose vacinal (experimento II). Os animais do grupo B1 e B2 (vacina oleosa) apresentaram níveis de anticorpos estatisticamente superiores $(\mathrm{P}<0,05)$ quando comparados aos dos grupos A1 e A2 (vacina aquosa) nos dois experimentos.

TERMOS DE INDEXAÇÃO: Mycoplasma agalactiae, agalaxia contagiosa, imunologia, adjuvante, anticorpos, vacina, caprinos. 


\section{INTRODUÇÃO}

Mycoplasma agalactiae é o principal agente etiológico da agalaxia contagiosa (AC), doença infecciosa de pequenos ruminantes, caracterizada por mastite, agalaxia, artrite e conjuntivite. A doença é endêmica em países do Mediterrâneo e causa perdas econômicas acentuadas devido à redução na produção de leite, aumento da mortalidade em animais jovens e redução da vida produtiva dos animais infectados (Madanat et al. 2001, Gil et al. 2003). Várias estratégias de prevenção têm sido empregadas para minimizar os impactos da doença, incluindo antibioticoterapia, abate ou sacrifício dos animais acometidos (Bergonier et al. 1997). 0 uso de bioterápico produzido a partir de M. agalactiae em caprinos clinicamente enfermos resultou no desaparecimento dos sinais clínicos, alem de ter sido de baixo custo para o produtor, com a vantagem de não produzir resíduos de drogas no leite (Marinho 2008).

Na Europa, as primeiras vacinas inativadas empregadas para controle da enfermidade datam da década de 1970 (Foggie et al. 1971). Vacinas vivas atenuadas foram também utilizadas, mas levantaram várias preocupações relacionadas com a inocuidade e eficácia, e não são permitidas em muitos países. Nos últimos anos, estudos foram realizados para desenvolver vacinas seguras e eficazes contra M. agalactiae (Leon-Vizcaino et al. 1995, Buonavoglia et al. 1998, Tola et al. 1999, Greco et al. 2002, De La Fe et al. 2007). As vacinas inativadas normalmente são combinadas com óleos minerais ou hidróxido de alumínio como adjuvantes para aumentar sua eficiência, influenciados pelos mecanismos de ação, vias de administração e imunidade requerida para cada tipo de vacina (Mota et al. 2006). Adjuvante oleoso induz uma resposta de anticorpos mais duradoura que o hidróxido de alumínio (Buonavoglia et al. 1998), mas produz reações locais que podem ser confundidas com abscessos ou provocar danos à musculatura, levando a perdas nas linhas de inspeção de carcaças.

No Brasil, a agalaxia contagiosa por M. agalactiae foi registrada em 2001 no Estado da Paraiba (Nascimento et al. 2002), e até o momento, parece estar restrita aos rebanhos do Nordeste. Por outro lado, não há vacinas disponíveis no mercado e não há nenhuma legislação específica quanto ao seu uso. Com este estudo objetivou-se avaliar a indução de anticorpos utilizando duas vacinas inativadas de origem européia, adsorvidas com adjuvante aquoso e oleoso para a prevenção da agalaxia contagiosa em caprinos.

\section{MATERIAL E MÉTODOS}

\section{Vacinas}

As vacinas foram fornecidas pelo Istituto Zooprofilático Sperimentale Della Puglia e Della Basilicata, Itália, para uso experimental em animais de áreas com diagnóstico da doença. A vacina aquosa continha hidróxido de alumínio como adjuvante, enquanto a oleosa continha óleo mineral.

\section{Animais}

Cabritos nascidos em áreas com diagnóstico positivo de agalaxia contagiosa foram utilizados para o experimento. Para garantir que as matrizes não tivessem contato com as crias, o parto foi induzido com a administração de 75mg de cloprostenol aos 145 dias de gestação. Os cabritos foram separados imediatamente da mãe e encaminhados para uma área distante quatro $\mathrm{km}$ do foco. Os recém-nascidos receberam colostro artificial produzido com leite de vaca pasteurizado, procedimento já adotado rotineiramente na Estação Experimental de Pendência da Empresa Estadual de Pesquisa Agropecuária - EMEPA. Os animais foram acompanhados diariamente para observação de alterações inerentes a agalaxia contagiosa.

\section{Teste de esterilidade, inocuidade e eficiência das vacinas}

A esterilidade foi verificada pela semeadura de $30 \mu \mathrm{l}$ de cada vacina em placas de petri contendo meio Hayflick modificado, agar sangue e agar sabouraund e incubadas por 21 dias a $37^{\circ} \mathrm{C}$.

Para o teste de inocuidade (Experimento I) foram utilizados 15 cabritos com 3-4 meses de idade. Os animais foram mantidos no Hospital Veterinário da Universidade Federal de Campina Grande (UFCG), em área separada onde não havia histórico da enfermidade, e subdivididos da seguinte forma:

Grupo A1 (vacina aquosa): cinco animais receberam duas doses de $2 \mathrm{~mL}$ da vacina aquosa com 14 dias de intervalo;

Grupo B1 (vacina oleosa): cinco animais receberam duas doses de $1 \mathrm{~mL}$ da vacina oleosa com 21 dias de intervalo;

Grupo C1 (controle): cinco animais que receberam duas doses de $2 \mathrm{ml}$ de solução salina fisiológica a 0,9\%.

Amostras de sangue foram coletadas no dia das vacinações e 30 dias após a segunda dose.

Para o teste de eficiência (Experimento II) foram utilizados 58 caprinos, machos e fêmeas, com 3-4 meses de idade, mantidos em regime semi-intensivo, em área separada de uma propriedade com histórico da enfermidade, subdivididos da seguinte forma:

Grupo A2 (vacina aquosa): Vinte e oito animais receberam três doses da vacina aquosa, sendo as duas primeiras com 14 dias de intervalo e um reforço aos 180 dias;

Grupo B2 (vacina oleosa): Trinta animais receberam três doses da vacina oleosa, sendo as duas primeiras com 21 dias de intervalo e um reforço aos 180 dias;

Todos os animas foram vacinados na região axilar e as amostras de sangue foram coletadas no dia de cada vacinação e 30 dias após a dose de reforço.

\section{Exame clínico}

Diariamente, todos os animais foram examinados para verificação dos parâmetros fisiológicos (temperatura retal, frequência cardíaca, frequência respiratória) e observação de qualquer alteração clínica sugestivo de agalaxia contagiosa.

\section{Sorologia}

Os níveis de anticorpos anti-M. agalactiae foram determinados pelo método ELISA indireto, conforme descrito por Campos et al. (2009). 0 ponto de corte adotado foi de 0,080 de densidade óptica (D0), calculado considerando a média dos percentuais de soros obtidos de 20 caprinos comprovadamente negativos mais três desvios-padrão, multiplicado por 2. Os soros foram colhidos de seis cabritos recém-nascidos, obtidos por parto induzido com separação imediata da cabra e alimentação com colostro artificial; de dois caprinos adultos do arquipélago de Fernando de Noronha, área sem registro da doença e de 12 caprinos adultos, de um rebanho monitorado e sem sinais clínicos da enfermidade, nem crescimento no cultivo de micoplasmas.

\section{Estatística}

Para a análise estatística foi utilizado o Modelo Linear Geral (General Linear Model - GLM) do SAS (2002), com efeitos interativos avaliados entre tratamentos (vacina aquosa ou oleosa) e 
intervalo das coletas, com comparações múltiplas pelo teste de Tukey e nível de significância de 5\%.

\section{RESULTADOS}

Não houve crescimento bacteriano e de fungos nas placas semeadas com as vacinas. Os animais vacinados não apresentaram alterações sistêmicas e os padrões fisiológicos (temperatura corporal, frequência cardíaca e respiratória) mantiveram-se dentro da normalidade para a espécie durante todo período experimental. A vacina oleosa produziu nódulos que variaram de 0,5 a $1,5 \mathrm{~cm}$ de diâmetro no local da administração, mas que desapareceram por volta de 30 dias após as vacinações.

A média dos títulos de anticorpos contra Mycoplasma agalactiae nos grupos vacinados estão demonstrados nas Figuras 1 e 2 . Os títulos de anticorpos antes da vacinação estavam abaixo do ponto de corte em todos os grupos. $\mathrm{Na}$ segunda e terceira doses, a vacina oleosa (B1 e B2) induziu níveis significativamente mais elevados de anticorpos, demonstrando ser mais eficaz que a vacina aquosa $(\mathrm{P}<0,05)$. Não houve diferença estatística entre o grupo A1 (vacina aquosa) e o grupo C1 (controle). Os animais do grupo B2 apresentaram redução dos títulos após seis meses do refor-

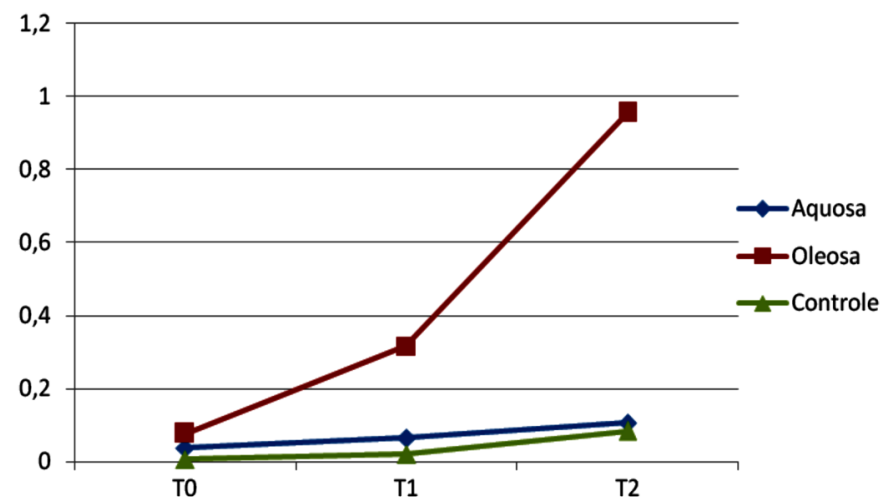

Fig.1. Média dos títulos de anticorpos contra Mycoplasma agalactiae dos caprinos do experimento I imunizados com vacina aquosa, oleosa e o grupo controle, de acordo com o período da vacinação (T0 = dia da primeira dose, T1 = dia da segunda dose, $\mathrm{T} 2=30$ dias após a segunda dose).

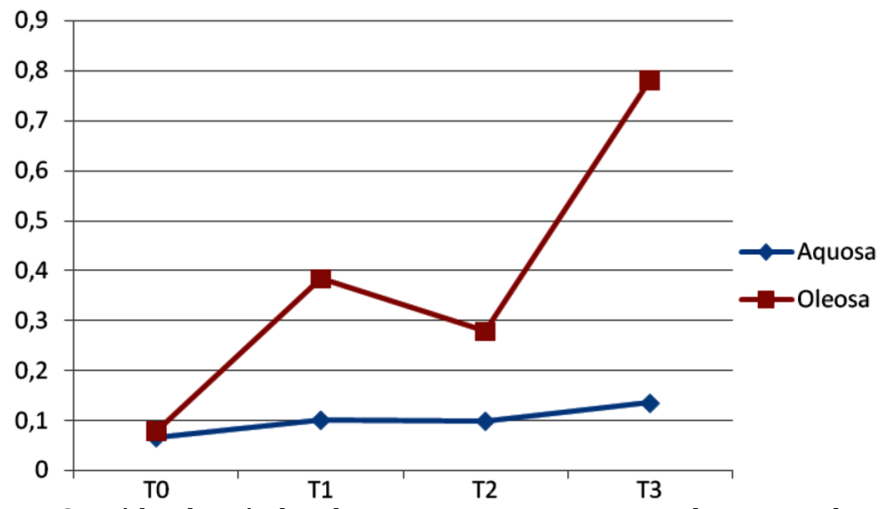

Fig.2. Média dos títulos de anticorpos contra Mycoplasma agalactiae dos caprinos do experimento II imunizados com vacina aquosa e oleosa, de acordo com o período de vacinação (T0 = dia da primeira dose, $\mathrm{T} 1$ =dia da segunda dose, $\mathrm{T} 2=$ dia da terceira dose, $\mathrm{T} 3=30$ dias após a terceira dose). ço vacinal, mas recuperaram rapidamente os títulos após a terceira dose (Fig.2).

\section{DISCUSSÃO}

Os títulos e persistência de anticorpos contra Mycoplasma agalactiae induzidos por vacina com adjuvante oleoso comprovaram a maior eficiência dessa formulação, quando comparada ao hidróxido de alumínio. Resultados semelhantes foram relatados por Greco et al. (2002) ao avaliarem a eficácia de uma vacina inativada com emulsão de óleo contra M. agalactiae em ovinos. Os autores observaram que os animais não apresentaram quaisquer sinais clínicos da doença, após o desafio.

De La Fe et al. (2006) em estudo realizado com cordeiros e cabritos utilizando vacinas combinadas de $M$. agalactiae e M. mycoides subsp. mycoides LC, observaram que os cabritos apresentaram níveis de anticorpos mais elevados que os cordeiros para ambos os antígenos. Vacinas inativadas preparadas com Montanide ISA-563, Marcol-52 e Montane-80, na proporção de 30, 63 e 7\%, respectivamente, foram capazes de induzir proteção clínica aos animais desafiados com M. agalactiae (Buonavoglia et al. 2008). Em outro estudo, o mesmo grupo de pesquisadores relatou que uma vacina contendo três adjuvantes oleosos foi capaz de induzir imunidade por até oito meses após a segunda dose vacinal (Buonavoglia et al. 2010).

A qualidade dos adjuvantes empregados nas formulações das vacinas para caprinos é uma questão que merece atenção, visto que a formação e permanência de nódulos vacinais podem interferir na aceitação do procedimento por parte dos criadores e no diagnóstico de doenças que apresentam abscessos subcutâneos como é o caso da infecção por Corynebacterium pseudotuberculosis. No segundo caso, pode-se evitar esse incoveniente pela administração da vacina na região axilar, como adotado no presente trabalho. Vale ressaltar que a formação do nódulo vacinal é um evento desejável, visto que a reação inflamatória local retém o antígeno no sítio de inoculação, permitindo um maior afluxo de células apresentadoras de antígenos, estimulando o organismo a produzir a resposta imune por períodos mais prolongados (Buonavoglia et al. 2008).

A redução dos títulos após a segunda dose, mesmo com a vacina oleosa, sugere que o intervalo entre as repetições a ser adotado devem ser definido para as condições do Brasil.

0 presente trabalho é o primeiro relato de vacinação contra agalaxia contagiosa no Brasil e pelos resultados apresentados, sugere-se que esta tecnologia deve ser adotada, a partir de vacinas produzidas com amostras de $M$. agalactiae isoladas em rebanhos nacionais na perspectiva de evitar a dependência de produtos importados.

\section{CONCLUSÃO}

A vacina contra Mycoplasma agalactiae produzida com adjuvante oleoso induziu níveis de anticorpos em caprinos mais elevados e mais duradouros que a vacina produzida com adjuvante aquoso.

Agradecimentos.- Ao Istituto Zooprofilático Sperimentale Della Puglia e Della Basilicata (Itália), pela gentileza do fornecimento das vacinas para a realização deste trabalho. A Emepa pelo fornecimento dos animais e instalações para realização do experimento. 


\section{REFERÊNCIAS}

Bergonier D., Berthelot X. \& Poumarat F. 1997. Contagious agalactia of small ruminants: current knowledge concerning epidemiology, diagnostic and control. Rev. Sci. Tech. Off. Epiz. 16:848-73.

Buonavoglia D., Fasanella A., Sagazio P., Tempesta M., Iovane G. \& Buonavoglia C. 1998. Persistent of antibodies to Mycoplasma agalactiae in vaccinated sheep. New Microbiol. 21(2):209-212.

Buonavoglia D., Greco G., Quaranta V., Corrente M., Martella V. \& Decaro N. 2008. An oil-emulsion vaccine induces full-protection against Mycoplasma agalactiae infection in sheep. New Microbiol. 31(1):117-123.

Buonavoglia D., Greco G., Corrente M., Greco M.F., D’Abramo M., Latronico F., Fasanella A. \& Decaro N. 2010. Long-term immunogenicity and protection against Mycoplasma agalactiae induced by an oil adjuvant vaccine in sheep. Res. Vet. Sci. 88(1):16-19.

Campos A.C., Teles J.A.A., Azevedo E.O., Nascimento E.R., Oliveira M.M.M., Nascimento S.A. \& Castro R.S. 2009. ELISA protein G for the diagnostic of contagious agalactia in small ruminants. Small Rumin. Res. 84:70-75.

De La Fe C., Rodriguez R., Assunção P., Ramirez A., Flores P. \& Poveda J.B. 2006. Humoral immune response in lambs and goats kids inoculated with dual vaccine against contagious agalactia. An. Vet., Múrcia, 22:87-91.

De La Fe C., Assunção P., Saavedra P., Tola S., Poveda C. \& Poveda J.B. 2007. Field Trial two dual vaccines against Mycoplasma agalactiae and Mycoplasma mycoides subesp. Mycoides (large colony type) in goats. Vaccine 25:2340-2345.

Foggie A., Etheridge J.R., Erdag 0. \& Arisoy F. 1971. Contagious agalactia of sheep and goats. Immunity of lactating ewes vaccinated before mating with live or dead vaccines. J. Comp. Pathol. 81(3):393-400.
Gil M.C., Peña F.J., Mendoza J.H. \& Gomez L. 2003. Genital lesions in an outbreak of caprine contagious agalactia caused by Mycoplasma agalactiae and Mycoplasma putrefaciens. J. Vet. Med. B 50(10):484.

Greco G., Corrente M., Buonavoglia D., Aliberti A. \& Fasanella A. 2002. Inactivated vaccine induces protection against Mycoplasma agalactiae infection in sheep. New Microbiol. 25(1):17-20.

Leon-Vizcaino L., Garrido Abellán F., Cubero Pablo M.J. \& Perales A. 1995. Immunoprophylaxis of caprine contagious agalaxia due to Mycoplasma agalactiae with an inactivated vaccine. Vet. Rec. 137:266-269.

Madanat A., Zendulková D. \& Pospíšil Z. 2001. Contagious agalactiae of sheep and goats: a review. Acta Vet. Brno 70:403-412.

Marinho M.L. 2008. Acão terapêutica do bioterapico de Mycoplasma agalactiae em caprinos (Capra hircus, Linnaeus, 1758) com agalaxia contagiosa dos ovinos e caprinos. Tese de Doutorado em Ciência Animal, Universidade Federal Rural de Pernambuco, Recife, PE. 123p.

Mota E.F., Lima M.G.S. \& Melo D.F. 2006. Adjuvantes Imunológicos: avanços e perspectivas. Ciência Animal 16(2):79-88.

Nascimento E.R., Barreto M.L., Platenik M.O., Azevedo E.O., Tabosa I.M., Alcântara M.D.B., Almeida J.F. \& Nascimento M.G.F. 2002. Contagious agalactia by Mycoplasma agalactiae in goats in Brazil. Etiologic study. In: Intern. XIV Congr. Int. Organiz. Mycoplasmol. (IOM), Vienna, p.45-46. (Resumo)

PROG. GLM (General-Linear-Models) do SAS 2002. SAS User's Guid): statistics. Statistical Analisys System, Versão 5. SAS, Cary.

Tola S., Manunta D., Rocca S., Mocchigiani A.M., Indini G., Angioi P.P. \& Leori G. 1999. Experimental vaccination against Mycoplasma agalactiae using different inactivated vaccines. Vaccine 17:2764-2768. 